\title{
PENGARUH PELAKSANAAN PENDAMPINGAN KADER TERHADAP KUNJUNGAN ANTENATAL CARE (ANC) IBU HAMIL RESIKO TINGGI DI MEGALUH JOMBANG
}

\section{THE INFLUENCE IMPLEMENTATION CADRE ASSISTANCE TO ANTENATAL CARE AT HIGH RISK PRENATAL WOMEN IN MEGALUH JOMBANG}

\author{
Kolifah \\ Program Studi DIII Kebidanan \\ Stikes Pemkab Jombang Jl. Dr. Sutomo No.75-77 Jombang \\ Email : kolifah0607@yahoo.com
}

\begin{abstract}
The maternal mortality rate (MMR) in Indonesia as one of the adult health indicators are still high when compared with other countries in ASEAN. Every pregnant women face the risk of death, so that the necessary efforts to improve the health status of pregnant women to maternity, is mentoring by volunteers. This study aims to investigate the influence implementation of assistance cadres to visit antenatal care (ANC) pregnant women at high risk. Research is correlational design with cross sectional approach. The subject of the study 29 pregnant women at high risk SPR score $\geq 10$ at second and third trimester pregnancy. The independent variable is the duty of cadres as facilitator, motivator, and mediator were obtained by interview and notebook cadres. The dependent variable is the ANC of books KIA pregnant women. Analyzed by frequency distribution, bivariate with a person product moment test, and multivariate logistic regression. The majority of cadres as active facilitator (63\%), almost entirely as an active motivator (86\%), almost entirely as an active mediator (83\%) and were mostly as a companion active (83\%). ANC high-risk pregnant women the majority $(66 \%)$ regularly. There is a mutual effect equally between tasks ANC cadres to visit pregnant women at high risk. The most influential is the duty of cadres as a companion. Community involvement ie cadres, community leaders and religious leaders in implementing health programs are required to enable achievement of the health targets can be maximized.
\end{abstract}

Keywords: Mentoring, ANC, high-risk pregnant women

Abstrak : Angka kematian ibu (AKI) di Indonesia sebagai salah satu indikator kesehatan dewasa ini masih tinggi bila dibandingkan dengan Negara di ASEAN lainnya. Setiap ibu hamil menghadapi resiko terjadinya kematian, sehingga diperlukan upaya meningkatkan status kesehatan ibu hamil sampai bersalin, yaitu pendampingan oleh kader. Tujuan penelitian ini adalah untuk mengetahui pengaruh pelaksanaan pendampingan kader terhadap kunjungan antenatal care (ANC) ibu hamil resiko tinggi di Megaluh Jombang. Jenis penelitian ini korelasional dengan pendekatan Cross Sectional. Subyek penelitian 29 ibu hamil resiko tinggi skor SPR $\geq 10$ pada usia kehamilan trimester 2 dan 3 . Variabel bebas adalah tugas kader yaitu sebagai fasilitator, motivator, mediator dan pendamping yang diperoleh dengan wawancara dan buku catatan kader. Variabel terikat adalah kunjungan ANC dari buku KIA ibu hamil. Data dianalisa dengan distribusi frekuensi, bivariate dengan uji person product moment, dan multivariate dengan uji regresi logistic. Gambaran tugas kader sebagain besar sebagai fasilitator aktif (63\%), hampir seluruhnya sebagai motivator aktif $(86 \%)$, hampir seluruhnya sebagai mediator aktif $(83 \%)$ dan sebagain besar sebagai pendamping yang aktif (83\%). Kunjungan ANC ibu hamil resiko tinggi sebagain besar (66\%) teratur. Ada pengaruh secara bersama sama antara tugas kader terhadap kunjungan ANC ibu hamil resiko tinggi. Variabel yang paling berpengaruh adalah tugas kader sebagai pendamping. Keterlibatan masyarakat yaitu kader, tokoh masyarakat dan tokoh agama dalam 
melaksanakan program kesehatan sangat diperlukan sehingga pencapain target kesehatan dapat maksimal.

Kata kunci : Pendampingan, ANC, ibu hamil resiko tinggi.

\section{PENDAHULUAN}

Angka kematian ibu (AKI) sebagai salah satu indicator kesehatan dewasa ini masih tinggi bila dibandingkan dengan Negara di ASEAN lainnya. Berdasarkan Survei Demografi dan Kesehatan Indonesia (SDKI) tahun 2012, angka kematian ibu (yang berkaitan dengan kehamilan, persalinan, dan nifas) sebesar 359 per 100.000 kelahiran hidup. (Profil Kesehatan Indonesia, 2013)

Angka Kematian Ibu merupakan salah satu indicator untuk melihat derajat kesehatan perempuan. (SDKI, 2012)

Data AKI di Kabupaten Jombang pada tahun 2013 sebanyak 18 kasus, 2014 sebanyak 26 kasus dan data terkini pada bulan Januari hingga Februari 2015 ini jumlah AKI sebanyak 6 kasus. Dari jumlah tersebut, penyebab kematian ibu terbesar diakibatkan karena hipertensi dalam kehamilan sebesar 39\%, 16\% disebabkan karena perdarahan dan sisanya dikarenakan penyebab lain. Penyebab kematian ibu dipengaruhi oleh banyak factor antara lain berasal dari kondisi kesehatan ibu, sumber daya kesehatan, sarana dan fasilitas pelayanan, social budaya masyaraat, ekonomi, pendidikan ibu. Faktor budaya masyarakat memiliki pengaruh yang cukup besar, oleh karena itu perlu adanya upaya meningkatkan peran serta masyarakat untuk turut serta dalam menurunkan jumlah kematian Ibu. (Dinas Kesehatan Kabupaten Jombang, 2015)

Salah satu program propinsi Jawa Timur yang telah dilaksanakan sejak tahun 2013 yaitu Gerakan Bersama Amankan Kehamilan (GEBRAK) dan pendampingan ibu hamil resiko tinggi. Jawa Timur merupakan satu satunya propinsi yang melaksanakan Program pendampingan ibu hamil. (Profil Dinas Kesehatan Propinsi Jawa Timur, 2014)

Kecamatan Megaluh kabupaten Jombang, merupakan kecamatan penyu bang AKI di kabupaten Jombang, pada tahun 2014 ada 3 kematian ibu. Penyebab kematian ibu adalah perdarahan dan Pre Eklamsia Berat (PEB). Tahun 2015 puskesmas Megaluh merupakan salah satu dari 10 puskesmas pelaksana program GEBRAK (Gerakan Bersama Amankan Kehamilan dan Persalinan) dikabupaten Jombang. Program GEBRAK dilakukan dengan pendampingan kepada $10 \mathrm{ibu}$ hamil resiko tinggi selama 10 bulan diawali di trimester 2 kehamilan. (Dinas Kesehatan Kabupaten Jombang, 2015)

Setiap ibu hamil menghadapi resiko terjadinya kematian, sehingga salah satu upaya menurunkan tingkat kematian ibu adalah meningkatkan status kesehatan ibu hamil sampai bersalin. Salah satu upaya untuk membantu ibu hamil terutama yang berisiko tinggi, maka diperlukan pendamping yang mengerti dan memahami social budaya masyarakat sehingga bisa memberikan informasi, bimbingan dan motivasi kepada ibu hamil dan keluarganya. (USAID, 2014) Pendamping yang ditunjuk adalah kader Posyandu yang akan mendampingi ibu hamil terutama yang beresiko tinggi mulai dari awal kehamilan sampai dengan masa nifas. (Dinas Kesehatan Kabupaten Jombang, 2015)

Kegiatan pendampingan ibu hamil resiko tinggi oleh kader Posyandu dilaksanakan sebagai salah satu upaya untuk memberdayakan masyarakat berperan dalam menurunkan jumlah kematian Ibu. Bentuk peran serta masyarakat dalam bidang kesehatan ibu dan bayi diantaranya dengan partisipasi anggota masyarakat sebagai kader. (Dinkes Kab Malang, 2015)

Peran kader dalam program kesehatan Ibu dan Anak adalah untuk menginformasikan segala perasalahan kesehatan yang berhubungan dengan kesehatan ibu hamil, bayi baru lahir serta mampu menjadi penggerak bagi kelompok 
atau organisasi masyarakat yang ada. Salah satu fungsi kader dalam kesehatan ibu dan anak adalah membantu memotivasi ibu hamil untuk melakukan pemeriksaan kehamilan di tenaga kesehatan. (Depsos RI, 2007)

Pendampingan dilakukan sejal awal kehamilan sampai dengan 40 hari setelah melahirkan. Selama ibu hamil kader melaksanakan pendampingan dengan cara memantau keadaan ibu dan memotivasi untuk melakukan pemeriksaan kehamilan secara rutin dan melahirkan di pelayanan kesehatan yang sesuai dengan resiko kehamilannya. Ibu hamil yang selalu melakukan pemeriksaan secara rutin akan terdeteksi lebih awal jika ada komplikasi kehamilan dan dapat segera dilakukan penatalaksanaan komplikasi kehamilan. (Dinas Kesehatan Kabupaten Jombang, 2015)

\section{METODE}

Jenis penelitian ini korelasional dengan pendekatan Cross Sectional. Subyek penelitian $29 \mathrm{ibu}$ hamil resiko tinggi skor SPR $\geq 10$ pada usia kehamilan trimester 2 dan trimester 3. Variabel bebas adalah tugas kader yaitu sebagai fasilitator, motivator, mediator dan pendamping yang diperoleh dengan wawancara dan buku catatan kader. Variabel terikat adalah kunjungan ANC.

Penelitian dilaksanakan mulai 26 Februari 2015 sampai Desember 2015.

Data dianalisa dengan distribusi frekuensi, bivariate dengan uji person product moment, dan multivariate dengan uji regresi logistic.

\section{HASIL PENELITIAN}

\section{A. Analisa Univariat}

\section{Distribusi frekuensi kader sebagai} fasilitator.

Tabel 1 Distribusi Frekuensi Kader Sebagai Fasilitator.

\begin{tabular}{llcc}
\hline No & Fasilitator & $\mathbf{f}$ & $\mathbf{( \% )}$ \\
\hline 1 & Aktif & 20 & 69 \\
\hline 2 & Pasif & 9 & 31 \\
\hline & Jumlah & 29 & 100 \\
\hline
\end{tabular}

\section{Sumber : Data Primer 2015}

Tabel 4.6 menunjukkan sebagian besar (69\%) kader sebagai fasilitator aktif.

\section{Distribusi frekuensi pernyataan kader sebagai motivator.}

Tabel 2. Distribusi Frekuensi Kader Sebagai Motivator.

\begin{tabular}{llll}
\hline No & Motivator & f & $(\%)$ \\
\hline 1 & Aktif & 25 & 86 \\
2 & Pasif & 4 & 14 \\
\hline & Jumlah & 29 & 100 \\
\hline
\end{tabular}

Sumber : Data Primer 2015

Tabel 2 menunjukkan hampir seluruhnya $(86 \%)$ kader sebagai motivator aktif.

\section{Distribusi frekuensi pernyataan kader sebagai mediator.}

Tabel 3 Distribusi Frekuensi Kader Sebagai Mediator.

\begin{tabular}{clcc}
\hline No & Mediator & Frekuensi & $(\boldsymbol{\%})$ \\
\hline 1 & Aktif & 24 & 83 \\
2 & Pasif & 5 & 17 \\
\hline & Jumlah & 29 & 100 \\
\hline
\end{tabular}

Sumber : Data Primer 2015

Tabel 3 menunjukkan hampir seluruhnya kader sebagai mediator aktif.

\section{Distribusi frekuensi kader sebagai pendamping}

Tabel 4. Distribusi Frekuensi Kader Sebagai Pendamping.

\begin{tabular}{clcc}
\hline No & Pendamping & f & $(\%)$ \\
\hline 1 & Aktif & 19 & 66 \\
2 & Pasif & 10 & 34 \\
\hline & Jumlah & 29 & 100 \\
\hline
\end{tabular}

Sumber : Data Primer 2015

Tabel 4 menunjukkan sebagian besar kader sebagai pendamping aktif. 
5. Distribusi frekuensi kunjungan ANC ibu hamil ke pelayanan kesehatan

Tabel 5. Distribusi Frekuensi Kunjungan ANC ibu hamil ke pelayanan kesehatan.

\begin{tabular}{llcc}
\hline No & Kunjungan ANC & f & $(\boldsymbol{\%})$ \\
\hline 1 & Teratur & 19 & 66 \\
\hline 2 & Tidak Teratur & 10 & 34 \\
\hline & Jumlah & 29 & 100 \\
\hline
\end{tabular}

Sumber : Data Primer 2015

Tabel 5 menunjukkan sebagian besar (66\%) ibu hamil teratur melakukan kunjungan ANC ke pelayanan kesehatan.

\section{B. ANALISA BIVARIAT}

1. Hubungan antara tugas kader dengan kunjungan ANC ibu hamil.

Tabel 6. Hasil uji pearson product moment tugas kader dan kunjungan ANC ibu hamil resiko tinggi.

\begin{tabular}{clcc}
\hline No & Tugas Kader & $\mathbf{p}$ & (rho) \\
\hline 1 & Fasilitator & 0,002 & 0,545 \\
\hline 2 & Motivator & 0,002 & 0,545 \\
\hline 3 & Mediator & 0,001 & 0,584 \\
\hline 5 & Pendamping & 0,000 & 1,000 \\
\hline
\end{tabular}

Tabel 6 hasil menunjukkan bahwa antara tugas fasilitator dengan kunjungan ANC diperoleh nilai $p$ value $=0,002(\mathrm{p} \leq 0,05)$. Hasil motivator dengan kunjungan ANC diperoleh nilai $p$-value $=0,002(\mathrm{p} \leq$ 0,05). Hasil mediator dengan kunjungan ANC diperoleh nilai $p$ value $=0,001 \quad(\mathrm{p} \leq 0,05)$. Hasil pendamping dengan kunjungan ANC diperoleh nilai $p$-value $=0,000(\mathrm{p} \leq$ $0,05)$.

\section{ANALISA MULTIVARIAT}

Tabel 7. Hasil Analisa Regresi Logistik Multivariat Pendampingan kader terhadap kunjungan ANC ibu hamil resiko tinggi, tahun 2015.

\begin{tabular}{|c|c|c|c|c|}
\hline \multirow[b]{2}{*}{ Variabel } & \multirow[b]{2}{*}{ Sig } & \multirow[b]{2}{*}{$\operatorname{Exp}(B)$} & \multicolumn{2}{|c|}{$95 \%$ CI $\operatorname{Exp}(B)$} \\
\hline & & & Lower & Upper \\
\hline Fasilitator & 0,034 & 6,717 & 1,156 & 39,042 \\
\hline Motivator & 0,022 & 5,930 & 1,300 & 27,050 \\
\hline Mediator & 0,022 & 6,158 & 1,304 & 29,073 \\
\hline Pendamping & 0,009 & 7,087 & 1,647 & 30,507 \\
\hline constant & 0,000 & 0,005 & & \\
\hline
\end{tabular}
analisis Regresi Logistik Multivariat, dapat diketahui bahwa variabel fasilitator, motivator, mediator dan pendamping memiliki nilai $p$-value $\leq 0,05$.

\section{PEMBAHASAN}

Hasil analisa dengan uji korelasi Pearson diperoleh nilai $p$-value $=0,002(\mathrm{p} \leq$ 0,05 ) artinya Ha diterima, sehingga hasil uji ini menunjukkan ada korelasi yang bermakna antara tugas kader sebagai fasilitator dengan kunjungan ANC ibu hamil ke pelayanan kesehatan. Kekuatan korelasi yang terjadi antara kedua variable tersebut bersifat sedang (rho $=0,545)$ dan arah korelasi positif.

Menurut Wiryasaputra (2006) sebagai fasilitator harus mampu mengetahui kebutuhan kliennya, mampu memberikan penjelasan, mampu memberikan saran sesuai dengan kebutuhan kliennya.

Hal ini sesuai dengan hasil penelitian bahwa kader yang memfasilitasi dengan baik akan membantu kebutuhan ibu hamil dalam melakukan pemeriksaan ANC, jika kader tidak maksimal dalam memfasilitasi ibu hamil maka ibu hamil yang didampinginya juga tidak tertarik untuk melakukan kunjungan secara teratur.

Hasil analisa dengan uji korelasi Pearson diperoleh nilai $p$-value $=0,002(\mathrm{p} \leq$ $0,05)$ artinya $\mathrm{Ha}$ diterima, hal ini menunjukkan ada korelasi yang bermakna 
antara tugas kader sebagai motivator dengan kunjungan ANC ibu hamil ke pelayanan kesehatan. Kekuatan korelasi yang terjadi antara kedua variable tersebut bersifat sedang (rho $=0,545)$ dan arah korelasi positif.

Menurut Wiryasaputra (2006) seorang motivator harus mampu mempengaruhi prilaku klien sehingga klien berprilaku positif sesuai yang diharapkan. Motivator harus memberikan dukungan kepada klien dan dibangkitkan keyakinannya yang salah selama ini.

Hal ini sesuai dengan hasil penelitian bahwa kader yang aktif memberikan motivasi akan mempengaruhi prilaku ibu hamil menjadi teratur untuk melakukan kunjungan ANC, sedangkan kader yang pasif dalam memotivasi ibu hamil maka ibu hamil yang didampinginya juga tidak termotivasi untuk melakukan kunjungan secara teratur.

Hasil analisa dengan uji korelasi Pearson diperoleh nilai $p$-value $=0,001(\mathrm{p} \leq 0,05)$ hasil uji ini menunjukkan ada korelasi yang bermakna antara tugas kader sebagai mediator dengan kunjungan ANC ibu hamil ke pelayanan kesehatan. Kekuatan korelasi yang terjadi antara kedua variable tersebut bersifat sedang $($ rho $=0,585)$ dan arah positif.

Menurut Wiryasaputra (2006) mediator mampu memberikan informasi yang diperlukan pihak keluarga mengenai kondisi klien dan kondisi lembaga, agar dapat memberikan pertimbangan yang tepat dalam menentukan tindakan demi kepentingan klien. kader kesehatan sebagai media perantara antara klien dengan petugas kesehatan sehingga terjalin komunikasi yang baik. Mediator akan menjadikan hubungan bersifat netral tidak memaksakan kehendak, tetapi membawa kearah yang positif.

Menurut Triatmi, 2016 bahwa prilaku kerja kader terhadap pelaksanaan program GEBRAK memerlukan kerjasama baik dengan kader yang lain, bidan, kepala puskesmas dan masyarakat.
Kader yang aktif sebagai mediator akan mengingatkan ibu hamil agar teratur dalam melakukan kunjungan ANC. Seorang mediator sebagai penengah antara ibu hamil dengan petugas kesehatan sehingga klien tidak merasa dipaksa dalam melakukan ANC. Tugas mediator juga melibatkan keluarga klien agar ikut mendorong ibu hamil melakukan kunjungan ANC secara teratur.

Hasil analisa dengan uji korelasi Pearson diperoleh nilai $p$-value $=0,000(\mathrm{p} \leq 0,05)$ artinya ada korelasi yang bermakna antara tugas kader sebagai fasilitator dengan kunjungan ANC ibu hamil ke pelayanan kesehatan. Kekuatan korelasi yang terjadi antara kedua variable tersebut bersifat sangat kuat $($ rho $=1,000)$ dan arah korelasi positif.

Menurut Nani 2012, menjadi kader merupakan salah satu wujud peran serta masyarakat dalam bidang kesehatan. Peran kader dalam program kesehatan ibu dan anak adalah untuk menginformasikan segala permasalahan kesehatan yang berhubungan dengan kesehatan ibu hamil, bayi baru lahir serta mampu menjadi penggerak bagi kelompok masyarakat yang ada.

Kader yang aktif melakukan pendampingan akan mempengaruhi ibu hamil untuk melakukan kunjungan ANC secara teratur. Kader yang tidak aktif melakukan pendampingan maka kliennya juga tidak teratur melakukan kunjungan. Kader yang secara rutin mendampingi dan mengantar ibu hamil ke pelayanan kesehatan dapat memastikan bahwa kliennya telah melakukan pemeriksaan

Hasil penelitian menunjukkan bahwa untuk meningkatkan kunjungan ANC ibu hamil resiko tinggi diperlukan pendampingan kader yang memiliki kemampuan aktif sebagai fasilitator, aktif sebagai motivator sehingga ibu hamil mendapatkan dorongan ke arah prilaku yang baik yaitu melakukan kunjungan ANC secara rutin, selain itu diperkukan kemampuan kader lainnya yaitu sebagai mediator yang aktif dan melakukan 
pendampingan pada saat ibu hamil melakukan kunjungan ANC ke pelayanan kesehatan.

Proses pendampingan sebagai bagian dari program outreach, sangat dipengaruhi oleh potensi sumber daya tenaga pendamping di lapangan. Kemampuan akan pengetahuan, sikap dan moral pendamping akan mempengaruhi keikutsertaan masyarakat sebagai dampingan yang memiliki permasalahan. Sebagai seorang pendamping tentunya telah memiliki peran dan tugas masingmasing. Peran pendamping yang jelas meningkatkan kinerja dari para pendamping dan petugas lapangan lainnya ketika sedang melakukan kegiatan pendampingan. Pendampingan sangat berkaitan dengan kehadiran seorang pendamping di lingkungan kelompok dampingan/klien yang menjalankan tugas dan kewajibannya. (PPKSM 2004)

Menurut Anung S, dalam kemenkes RI, 2014, menyatakan bahwa kader masyarakat sangat penting dalam upaya menyelamatkan ibu hamil melalui pendampingan satu kader mendampingi satu ibu hamil resiko tinggi. Pendampingan dilakukan sejak awal kehamilan sampai dengan 40 hari setelah melahirkan. Kegiatan pendampingan juga diintegrasikan dengan kegiatan yang ada di masyarakat seperti Posyandu, dasawisma, Program Perencanaan Persalinan dan Pencegahan Komplikasi (P4K) serta pemberian informasi secara aktif terhadap orang tua agar mencegah pernikanan dini dikalangan remaja.

Kader kesehatan sangat diperlukan dalam memudahkan kegiatan kesehatan yang ada dimasyarakat. Kader merupakan anggota masyarakat sehingga mudah dalam melaksanakan tugasnya. Kader kesehatan yang aktif di masyarakat akan membawa perubahan prilaku di masyarakat tersebut. Pendamping berperan aktif sebagai agen yang memberikan masukan positif dan direktif berdasarkan pengetahuan dan pengalamannya serta bertukar gagasan dengan pengetahuan dan pengalaman masyarakat yang didampinginya, membangkitkan kesadaran masyarakat, menyampaikan informasi, melakukan konfrontasi, menyelenggarakan pelatihan bagi masyarakat adalah beberapa tugas yang berkaitan fungsi kader sebagai pendamping. Kader yang mendampingi ibu hamil resiko tinggi diharapkan dapat membantu bidan atau tenaga kesehatan memantau ibu hamil resiko tinggi sehingga ibu dapat menjalani proses kehamilan dengan baik dan melahirkan dengan selamat. Kader dan tenaga kesehatan perlu bekerja sama dalam menjalankan tugasnya di masyarakat sehingga dapat mewujudkan masyarakat yang sehat.

\section{KESIMPULAN DAN SARAN KESIMPULAN}

1. Gambaran tugas kader sebagain besar sebagai fasilitator aktif (63\%), hampir seluruhnya sebagai motivator aktif (86\%), hampir seluruhnya sebagai mediator aktif (83\%) dan sebagain besar sebagai pendamping yang aktif $(83 \%)$.

2. Kunjungan ANC ibu hamil resiko tinggi sebagain besar (66\%)teratur dalam melakukan kunjungan ke palayanan kesehatan.

3. Ada hubungan antara tugas kader sebagai fasilitator dengan kunjungan ANC ibu hamil resiko tinggi $(\mathrm{p}=$ 0,002 )

4. Ada hubungan antara tugas kader sebagai motivator dengan kunjungan ANC ibu hamil resiko tinggi $(\mathrm{p}=$ 0,002 )

5. Ada hubungan antara tugas kader sebagai mediator dengan kunjungan ANC ibu hamil resiko tinggi $(\mathrm{p}=$ 0,001 )

6. Ada hubungan antara tugas kader sebagai pendamping dengan kunjungan ANC ibu hamil resiko tinggi $(\mathrm{p}=$ $0,000)$

7. Ada pengaruh secara bersama sama antara tugas kader sebagai fasilitator $(\mathrm{p}$ $=0,034, \operatorname{Exp}(\mathrm{B})=6,717)$, sebagai motivator $(p=0,022, \operatorname{Exp}(B)=5,930)$, 
sebagai mediator $(\mathrm{p}=0,022, \operatorname{Exp}(\mathrm{B})=$ $6,158)$ dan sebagai pendamping $(\mathrm{p}=$ $0,009, \operatorname{Exp}(\mathrm{B})=7,087) \quad$ terhadap kunjungan ANC ibu hamil resiko tinggi. Variabel yang paling berpengaruh adalah tugas kader sebagai pendamping.

\section{SARAN}

1. Program pendampingan GEBRAK perlu dilaksanakan lebih luas kepada semua ibu hamil walaupun tidak masuk pada kategori resiko tinggi.

2. Pendampingan ibu hamil perlu melibatkan pihak lain selain kader agar semua ibu hamil dapat didampingi, salah satunya melibatkan institusi kesehatan yang ada di wilayah setempat.

\section{DAFTAR PUSTAKA}

Dinas Kesehatan Kabupaten Jombang. (2015) Profil Kesehatan Kabupaten Jombang.

Dinas Kesehatan, P.J.T. (2014) Profil Kesehatan Propinsi Jawa Timur. Jawa Timur.

Departemen Kesehatan Republik Indonesia. (2013) Profil Departemen Kesehatan RI, Jakarta.

Depertemen Sosial RI. (2004) Pusat Pengembangan Ketahanan Sosial Masyarakat (PPKSM). Bimbingan Sosial TKSM Model Peningkatan Ketahanan Sosial Masyarakat (Replikasi). Jakarta: Depsos RI

Depertemen Sosial RI. (2007) Pedoman Tenaga Pendamping Lapangan Perempuan, Jakarta: Depsos RI.

Kementrian Kesehatan RI., (2012) Survei Demografi Kesehatan Republik Indonesia.

Kementrian Kesehatan RI., (2014) Senyum Keluarga Posyandu untuk selamatkan Ibu. Dipublikasikan rabu $15 \quad$ Oktober 2014 http://www.depkes.go.id/article/print /201410270005/senyum-keluargaposyandu-untuk-selamatkan-ibu.html

Khomsah, Nani. (2012) Faktor faktor yang berhubungan dengan peran serta kader posyandu dalam deteksi faktor resiko ibu hamil di wilayah Puskesmas Buayan Kebumen Jawa Tengah. FKM UI.

Triatmi Andri Yanuarini, M.Keb, Reni Triwahyuningsih SSiT, M.Kes. Pengaruh motivasi internal terhadap kinerja kadr dalam program GEBRAK (Gerakan Bersama Amankan Kehamilan dan Persalinan) di wilayah Puskesmas Blabak Kab. Kediri. Jurnal Ilmu Kesehatan Vol. 5 No. 1 Nopember 2016

USAID. (2011) Buku Saku Motivator Kesehatan Ibu dan Anak. Jakarta.

Wiryasaputra, Totok.S. (2006) Ready to Care: Pendampingan dan Konseling Psikologis. Yogyakarta: Galang Press. 